\title{
Recursos Educativos en Abierto (REA) en Educación Infantil: características tecnológicas, didácticas y socio-comunicativas
}

\author{
Open Educational Resources (OER) in Early Childhood Education: \\ technological, didactic and socio-communicative characteristics
}

Anabel Bethencourt-Aguilar

Departamento de Didáctica e Investigación educativa, Universidad de La Laguna, España abethenc@ull.edu.es

\section{María Inmaculada Fernández-Esteban}

Departamento de Didáctica e Investigación educativa, Universidad de La Laguna, España mesteban@ull.edu.es

\section{Carlos José González Ruiz}

Departamento de Didáctica e Investigación educativa, Universidad de La Laguna, España cgonzalr@ull.edu.es

\section{Sebastián Martín-Gómez}

Departamento de Didáctica e Investigación educativa, Universidad de La Laguna, España smarting@ull.edu.es

\section{RESUMEN}

En este artículo se presenta un análisis de materiales didácticos digitales insertos en la plataforma del Instituto Nacional de Tecnologías Educativas y de Formación del Profesorado (INTEF) dirigidos especialmente a la etapa infantil. Este estudio, de tipología cualitativa, se enmarca en el proyecto de investigación denominado "Los materiales didácticos digitales en la Educación Infantil. Análisis y propuestas para su uso en la escuela y el hogar” (RTI2018-093397-B-100) financiado por la Agencia Estatal de Investigación del Ministerio de Ciencia, Innovación y Universidades. La muestra seleccionada comprenderá los Recursos Educativos en código abierto (REA) disponibles en esta plataforma, escogiendo una muestra representativa en función de las áreas de conocimiento en la Educación Infantil. Estos materiales didácticos digitales se analizan a partir de un análisis categórico de su tendencia metodológica subyacente, de la tipología y características técnicas y de diseño de los materiales, así como de las características sociocomunitativas inherentes en los recursos de aprendizaje diseñados, entre otras dimensiones y categorías. Entre los resultados, se destaca la diversidad de materiales didácticos digitales en función del área de conocimiento, y la falta de profundización en el desarrollo evaluativo de la propuesta didáctica planteada o en la evaluación propia de estos materiales.

PALABRAS CLAVE materiales multimedia, material didáctico, educación de la primera infancia, tecnologías de la información.

\section{ABSTRACT}

This article presents an analysis of digital teaching materials inserted in the platform of the National Institute of Educational Technologies and Teacher Training (INTEF) aimed especially at the infant stage. This qualitative typology study is part 
of the research project called "Digital teaching materials in Early Childhood Education. Analysis and proposals for its use at school and at home "(RTI2018-093397-B-100) funded by the State Research Agency of the Ministry of Science, Innovation and Universities. The selected sample will comprise the Open Source Educational Resources (OER) available on this platform, choosing a representative sample based on the areas of knowledge in Early Childhood Education. These digital didactic materials are analyzed based on a categorical analysis of their underlying methodological trend, the typology and technical and design characteristics of the materials, as well as the socio-community characteristics inherent in the designed learning resources, among other dimensions and categories. Among the results, the diversity of digital didactic materials according to the area of knowledge stands out, and the lack of depth in the evaluative development of the proposed didactic proposal or in the own evaluation of these materials.

KEYWORDS multimedia materials, teaching materials, early childhood education, information technology.

\section{INTRODUCCIÓN}

\subsection{La sociedad digital y la pedagogía de aprendizaje activo con tecnología desde la Educación Infantil}

La omnipresencia de la tecnología en todos los ámbitos y contextos de la sociedad ha hecho necesario que la educación se sumerja en un mar de constantes intentos por actualizarse para dar respuesta a las demandas formativas que las nuevas generaciones demandan. En el último lustro, se ha hecho necesario renovar contenidos y metodologías a fin de que todos los individuos puedan desarrollar las habilidades necesarias para desenvolverse en un ecosistema cada vez más digital. En este sentido, el movimiento por introducir la tecnología en las etapas más tempranas del sistema educativo, como es la Educación Infantil, se ha hecho notable. Area (2019) describe cómo el desafío de integrar los recursos y tecnologías digitales en las aulas debería favorecer la creación de espacios de aprendizaje más ricos, en el que el alumnado aprenda mediante la creación, producción y construcción de conocimientos. Para desarrollar una pedagogía activa con tecnología, se debe tener como pilares fundamentales algunas consignas: organizar tareas y actividades que involucren el uso de tecnología y requieran de procesos de aprendizaje colaborativo entre los estudiantes, plantear problemas o proyectos significativos para que el alumnado pueda articular planes de trabajo y llevar a cabo las acciones necesarias con tecnologías para obtener respuestas, o desarrollar metodologías apoyadas en recursos de distintos formatos e incentivar la producción de contenidos por parte del alumnado, mientras que el profesorado ejerce un papel de guía del aprendizaje.

Como bien sostienen Caldeiro-Pedreira y Castro-Zubizarreta (2020), este uso de recursos digitales en cualquier etapa educativa debe atender a una adecuada alfabetización mediática y digital. Una alfabetización que permita llegar a los objetivos inmediatos propios de la sociedad del conocimiento en la que vivimos. Atendiendo a esta realidad, la escuela y el contexto educativo deben también atender a formar en el uso correcto de la tecnología desde las primeras edades.

La integración curricular de la tecnología pasa por políticas educativas que tratan de respaldar el buen desarrollo de la competencia digital del alumnado y un uso crítico de las tecnologías de la información y la comunicación. Para este fin, existen diversos planes por parte de las instituciones educativas y administraciones públicas. En el caso de España, la administración pública, por medio del Instituto Nacional de tecnolo- 
gías educativas y formación del profesorado (INTEF), ha promovido una filosofía de conocimiento abierto en torno a los recursos digitales para enseñanza. Es por ello por lo que se ha incentivado el diseño de Recursos Educativos Abiertos (REA en adelante) como material didáctico digital, que permita al profesorado integrar de forma crítica la tecnología en su práctica de aula. Este movimiento pasa por "crear, compartir, usar, recrear y volver a compartir" como bien describe Pastrana (2018, p. 2). Los REA son definidos por la UNESCO (2002) como "recursos educativos que se proveen en abierto, habilitados por las tecnologías de información y comunicación, para consulta, uso y adaptación por una comunidad de usuarios para fines no comerciales” (p. 24).

\subsection{Materiales didácticos: hacia el futuro}

Los materiales o medios de enseñanza en el ámbito educativo son una parte fundamental de los procesos de enseñanza/aprendizaje en todas las etapas educativas, además de seguir siendo objeto de estudio por parte de los investigadores de esta rama. Un buen ejemplo es el libro editado por Rodríguez et al. (2019), titulado " 25 Years developing textbook and educational media research", donde diferentes autores realizan un recorrido sobre aquellos aspectos más importantes relacionados con la temática que aquí se presenta.

Es interesante apuntar además a la clasificación de Hansen (2010, citado en 2019) en la que establece una serie de términos que permite agrupar los conceptos de "recursos de aprendizaje" y "medios digitales" con una terminología más precisa, lo que permite analizar diferentes tipos de materiales de aprendizaje en función de su finalidad en un contexto educativo:

- Materiales didácticos de aprendizaje, que se caracterizan por tener la intencionalidad didáctica codificada en el material, de modo que tenga una didáctica incorporada que atienda sistemáticamente a tareas docentes.

- Materiales de aprendizaje semántico, caracterizados por tener un contenido significativo, pero sin didáctica incorporada. La intencionalidad didáctica está así ligada al encuadre didáctico que el profesorado quiera desarrollar.

- Materiales de aprendizaje funcional, los cuales tampoco tienen didáctica incorporada, pero funcionan como herramientas que se utilizan para manejar contenidos y procesos de trabajo en la enseñanza a través de una o más de las siguientes funciones: producción, recepción, comunicación, evaluación, compensación, búsqueda, recolección de datos, etc.

Los materiales educativos en la educación infantil han sufrido una transformación radical en los últimos años (Gabarda et al., 2021). Aunque muchos de los materiales expuestos con anterioridad siguen siendo muy usados en dicha etapa, es necesario establecer una clasificación más precisa en cuanto a nuestro objeto de estudio, los Materiales Didácticos Digitales (MDD en adelante). A fin de clasificar los recursos, se ha tomado en consideración la propuesta de Area (2017) para la tipología de materiales didácticos: Objeto digital, Objeto digital de aprendizaje, Material Didáctico Digital, Materiales profesionales de docentes y Apps, herramientas y plataformas online.

\subsection{Criterios de calidad para la evaluación de los MMD}

La Asociación Española de Normalización es el único Organismo de Normalización en España y, como tal, ha sido designado por el Ministerio de Economía, Industria y Competitividad ante la Comisión Europea. Una de 
TABLA 1. Criterios de calidad de los MDD según Norma 71362

\begin{tabular}{|c|c|}
\hline \multicolumn{2}{|c|}{$\begin{array}{l}\text { Evaluación de recursos educativos según la Norma } 71362 \\
\text { de "Calidad de los materiales educativos digitales" }\end{array}$} \\
\hline Criterio 1 & Criterio 9 \\
\hline Descripción didáctica & Portabilidad \\
\hline Criterio 2 & Criterio 10 \\
\hline Calidad de los contenidos & $\begin{array}{c}\text { Robustez; } \\
\text { estabilidad técnica }\end{array}$ \\
\hline Criterio 3 & Criterio 11 \\
\hline $\begin{array}{c}\text { Capacidad para generar } \\
\text { aprendizaje }\end{array}$ & $\begin{array}{l}\text { Estructura del escenario } \\
\text { de aprendizaje }\end{array}$ \\
\hline Criterio 4 & Criterio 12 \\
\hline Adaptabilidad & Navegación \\
\hline Criterio 5 & Criterio 13 \\
\hline Interactividad & Operabilidad \\
\hline Criterio 6 & Criterio 14 \\
\hline Motivación & $\begin{array}{c}\text { Accesibilidad del contenido } \\
\text { audiovisual }\end{array}$ \\
\hline Criterio 7 & Criterio 15 \\
\hline Formato y diseño & $\begin{array}{c}\text { Accesibilidad del contenido } \\
\text { textual }\end{array}$ \\
\hline
\end{tabular}

Criterio 8

Reusabilidad sus funciones es publicar normas que tienen como objeto contribuir al desarrollo de los sectores de actividad, a través de las normas técnicas, orientando los esfuerzos de todas las partes interesadas.

Una de las reglas que han realizado es la Norma 71362 de "Calidad de los materiales educativos digitales". El objetivo de esta guía es proporcionar un modelo y herramienta para evaluar la calidad de los Materiales Educativos Digitales (MED en adelante), creados y utilizados en los entornos de enseñanza y aprendizaje electrónicos. Esta normativa integra quince criterios para valorar si un material didáctico digital es de calidad:

Según estos criterios, un recurso educativo digital es de calidad si es eficaz didáctica y tecnológicamente, y es accesible. Este fin se pretende lograr guiando la creación de MED de calidad; valorando los MED creados por los profesores, las instituciones, organismos, empresas y otros; ayudando a los usuarios a seleccionar los mejores MED; y, por último, contribuyendo a evaluar de forma más precisa, objetiva y completa las acciones y ofertas de enseñanza-aprendizaje electrónicos en base a la calidad de los MED como elemento constitutivo básico.

\subsection{Los repositorios institucionales: la apuesta pública por los MMD}

Los MDD aquí expuestos, independientemente de quién los haya elaborado, son alojados en diferentes plataformas o portales. Durante los últimos años, tanto el Ministerio de Educación, como las diferentes comunidades autónomas, han generado espacios, para que, cualquier usuario interesado en el ámbito de la educación pueda compartir sus materiales en la red.

Durante los últimos años, autores del ámbito nacional, han realizado diferentes estudios sobre dichos repositorios institucionales (Peirats, \& Eirin, 2019; Sanabria et al., 2017, Santana et al., 2017), como en los Portales Autonómicos de Canarias, Galicia y la Comunidad Valenciana. Las principales conclusiones de dichas investigaciones se centran en los siguientes aspectos:

- Las administraciones educativas están apostando por el desarrollo de las tecnologías digitales, y un ejemplo de ello es la producción y distribución de MDD a través de los portales educativos.

- Rendir cuentas de las inversiones realizadas (ordenadores, redes, software, materiales, etc.).

- La estructura de los portales tiene un carácter informativo, pero a la vez, también formativo, aunque este último ha tenido menos desarrollo. 
Siguiendo la misma línea, destacar el estudio realizado por Chirino et al. (2018), que versa sobre un análisis del portal perteneciente al INTEF, que lleva el nombre de Procomún y que cobra especialmente relevancia en este artículo porque nuestro objeto de investigación se centra en el análisis de MDD alojados en este mismo portal. Entre las principales conclusiones, por una parte, se afirma que, aunque el entorno tiene un mejor diseño que los anteriores, es necesario una actualización de los recursos educativos allí alojados. Además, los recursos educativos, al no tener una guía de orientación de su adaptación, no generan cambios significativos en los procesos de enseñanza/aprendizaje, convirtiéndose de esta manera en grandes repositorios de recursos, que no implican un cambio metodológico en las aulas.

En definitiva, observamos que las instituciones públicas están realizando un esfuerzo considerable en relación con la inversión destinada, pero que esta misma no está produciendo un cambio significativo, al menos, en los estudios reflejados con anterioridad. Es nuestro interés con este artículo, corroborar lo investigado hasta el momento, y ofrecer una visión más amplia de los MDD alojados en el portal educativo perteneciente al Ministerio de Educación y Formación Profesional.

\section{METODOLOGÍA}

El trabajo que presentamos está basado en un análisis de contenido cualitativo descriptivo, en función de las categorías deductivas definidas en este mismo apartado. Para hacer la selección, se han tenido en cuenta como criterios de exclusión las dificultades en el acceso, enlaces incorrectos o la necesidad de descargar complementos para la visualización de los contenidos del material presentado. Como criterios de selección, por el contrario, se han considerado aquellos materiales educativos o lúdicos que responden a los tres ámbitos de la Educación Infantil: Conocimiento de sí mismo, Conocimiento del entorno y Lenguaje: comunicación y representación.

El muestreo ha sido probabilístico (Recursos Educativos en Abierto del INTEF, del ciclo de Educación Infantil), estratificado simple por áreas de conocimiento. Dentro de las áreas de conocimiento, se ha procurado elegir aquellos materiales diversos, de distinto contenido educativo: matemáticas ( $n=3)$, español como lengua extranjera $(n=1)$, lenguaje y literatura $(n=9)$, educación ambiental $(n=4)$, educación sexual y para la salud $(n=1)$, expresión plástica $(n=1)$, tutoría $(n=1)$, educación cívica $(n=2)$, historia $(n=1)$ y, además, un material que recoge varias áreas en él destinados a las Necesidades Educativas Especiales ( $n=1)$. En total se han analizado 24 materiales para este artículo.

Las categorías analizadas han sido:

- Estructura del material: describiendo las secciones más relevantes, como la organización del menú principal, mapa de navegación, estructura de contenidos y las actividades. En esta categoría, se trata de hacer una descripción organizativa del material y de poner en valor aquellos elementos por los que destaca.

- Dimensión tecnológica: hace referencia a las características tecnológicas como la navegabilidad, si es o no un material multiplataforma y cuáles son las plataformas que lo componen, la velocidad de carga, interactividad, accesibilidad a la información considerando las características evolutivas del alumnado de esta etapa, así como los formatos o lenguajes empleados. 
- Dimensión del diseño: en esta categoría, se identifican las características del diseño y de funcionalidad más destacadas del material como, por ejemplo, el atractivo de su diseño, facilidad de uso, originalidad, tipografía, botones, claridad de la estructura y accesibilidad, así como la adecuación del diseño a las características psicoevolutivas del alumnado y facilitador de la comprensión de los contenidos.

- Dimensión pedagógica: en primer lugar, se trata de identificar si el material tiene una finalidad lúdica y/o educativa. Se describen las características didácticas más destacables del material como, por ejemplo, la organización del contenido, desarrollo de competencias, estrategia metodológica, actividades propuestas, objetivos y agrupamiento. De manera concreta, trata de identificar si se abordan temas transversales, si los contenidos están relacionados con el entorno del alumnado, si permite o no el uso autónomo del alumnado o requiere de la intervención o supervisión de personas adultas.

- Dimensión del contenido: en esta dimensión, se analiza si el material responde a las demandas curriculares de la etapa educativa, si incluye ámbitos del saber o conocimiento de distinta naturaleza y si expresa la lógica que organiza y secuencia el contenido. La identificación del alumnado de esta etapa por medio de los contenidos se tiene en cuenta a través del análisis del contenido icónico y textual. De este modo, se pretende comprobar si estos contenidos facilitan la diversidad sociocultural, si favorecen un tratamiento diferenciado en función del contexto social, cultural y ambiental de la aplicación, la descripción de la tipología de personajes o si refleja la diversidad funcional, sexual, cultural o etaria.

- La evaluación y seguimiento: por medio de la descripción de esta categoría, se pretende conocer si el material detalla los criterios y estrategias de evaluación, si propone actividades de evaluación y de qué tipo y si cuenta con feedback sonoro o visual.

Otras dos categorías a analizar de manera amplia, en la interpretación, son las que hacen referencia a los aspectos positivos o fortalezas y los aspectos negativos o debilidades.

El análisis se ha realizado mediante una matriz de doble entrada, en la que aparecen, por un lado, las categorías y, por el otro, los MDD analizados.

\section{RESULTADOS}

A continuación, se presentan los principales resultados de cada una de las categorías de análisis.

\subsection{Estructura de los materiales}

Comenzando por la estructura de estos MDD, la gran mayoría de los materiales seleccionados y analizados son recursos creados con la herramienta digital exelearning $(n=17)$, por lo que tienen una estructura delimitada similar. Estos recursos integran una división por secciones orientadas a mostrar información y contenido concreto sobre el recurso. Suelen estar divididos en las primeras secciones por un apartado introductorio donde se especifica la temática, los objetivos, el nivel educativo al que está dirigido el recurso, los contenidos relacionados y una mención a la metodología didáctica. En secciones continuas, la información presentada muestra la descripción de las actividades propuestas en el marco didáctico del recurso y, en muchos MDD, integran además actividades evaluativas automatizadas tipo cuestionario ( $n=13)$. En general, son menos los recursos que recogen un apartado específico con recursos complementarios para la propues- 
ta didáctica $(n=8)$ y menos aún los que disponen de recomendaciones en torno a la atención a la diversidad y a las necesidades educativas específicas. Por último, se puede encontrar apartados con menciones dirigidas a la evaluación y a las fuentes, autoría y licencias de uso del recurso.

Además de los recursos tipo exelearning, hay una minoría de recursos educativos que constan de características distintas $(n=7)$. En algunos de los MDD presentados, son recursos creados por otras plataformas o herramientas como Java o Genial.ly. En el caso del primero, son propuestos por instituciones como las del País Vasco que, a través de Adobe Flash Player, permitía su visualización. En el caso de los otros recursos creados en la herramienta Genial.ly, los analizados siguen una secuencia en torno a la presentación de los elementos más relevantes de la propuesta didáctica especificada: mención a los objetivos, contenidos, una propuesta de actividades a realizar y unos criterios para la evaluación. Estos dos tipos de recursos se estructuran de forma distinta a los exelearning pero mantienen la misma lógica y contenido relacionado con los apartados relevantes para cualquier propuesta didáctica.

\subsection{Dimensión tecnológica}

En cuanto a la dimensión tecnológica, la navegabilidad de los recursos analizados es sencilla e interactiva, aunque se valora si puede ser utilizado por el alumnado de Educación Infantil. En gran parte de estos recursos, su navegabilidad depende de la adquisición de un nivel adecuado en torno a la lectoescritura, cuestión que en esta etapa se está empezando a desarrollar. No obstante, algunos recursos complementarios insertos al REA pueden ser utilizados por el profesorado en la práctica de aula o favorecer que el alumnado utilice ciertas secciones del material con la atención y supervisión del profesorado. Por otro lado, la interactividad de los REA analizados, dependerá de los materiales insertos y la diversidad de los formatos de éstos. Esto es especialmente relevante si lo que se pretende es que el alumnado haga un uso más autónomo de los recursos. En este sentido, algunos recursos sí presentan ciertas características interactivas para las edades en el marco de la etapa Infantil y otras, no parecen ser adecuadas para ser usadas directamente por el alumnado.

Con respecto a la diversidad de formatos, se encuentran REA que presentan vídeos, audios, imágenes que favorecen la adquisición de la información de distinta forma, cuestión también esencial para la atención a la diversidad, aunque no se especifique directamente en los recursos. Los materiales más interactivos para el alumnado de infantil son aquellos que, precisamente, no son exelearning y que, además, adquieren una navegabilidad e interactividad mucho más visual e intuitiva.

Si se visualizan de forma correcta los recursos en la plataforma Procomún, la velocidad de carga es buena y no se encuentran problemas técnicos destacables. No obstante, algunos recursos que han sido analizados ya no pueden visualizarse porque el Adobe Flash Player que hasta el momento posibilitaba su visualización, ya no está disponible. Por otro lado, en el caso de los recursos exelearning, se encuentran problemas técnicos destacables en la carga del recurso dentro de la plataforma Procomún, por lo que complejiza bastante la consulta y utilización de estos recursos en un supuesto práctico real.

\subsection{Dimensión del diseño}

Por otro lado, el diseño estético de estos REA varía en función del formato con el que han sido creados. En los recursos de tipología exelearning, las plantillas utilizadas son, normalmente, neutras y limpias, lo que 
resulta adecuado e interesante para destinatarios más adultos. Por ello, se valora positivamente cuando se añaden imágenes, vídeos, y tipografías que acercan el material a las edades de destino. Sin embargo, en algunos REA se encuentran imágenes de baja calidad o vídeos con estéticas no homogéneas $(n=4)$. En los REA exelearning, se aprecia visualmente que la mayoría de los materiales incluyen recursos creados por terceras personas, lo que genera una ruptura en la estética homogénea o en la vinculación directa con la temática que se pretende trabajar. En pocos recursos de este tipo, se incluyen plantillas más personalizadas con colores más vivos que pueden resultar más atractivos para niños y niñas de Infantil ( $n=9)$.

Los recursos que no son exelearning, en cambio, presentan una interfaz más atractiva, con contrastes más altos en los colores, e incorporan elementos visuales y botones. Estos elementos son especialmente relevantes en los materiales procedentes de Genial.ly, favoreciendo la incorporación de enlaces en los botones que mejoran la navegabilidad por el recurso y dota de mayor dinamismo al material. Los recursos de tipología cerrada o los altamente interactivos (realizados en Genial.ly) incluyen una estética más homogénea, ya que todos los materiales que presentan son creados por la misma institución o por la misma persona.

\subsection{Dimensión pedagógica}

Del análisis de la dimensión pedagógica se concluye que la gran mayoría de los recursos seleccionados tienen una finalidad educativa. Sólo en algunos casos la finalidad es, además, lúdica ( $n=2)$, o, por el contrario, se puede considerar solo lúdica $(n=1)$. En términos generales, se valoran positivamente los materiales que favorecen el aprendizaje por descubrimiento, aquellos que son manipulables por el alumnado, interactivos y accesibles en el manejo por representar una interfaz intuitiva, así como la utilización de diferentes recursos y actividades dentro de un mismo material, la variedad de actividades y aplicaciones dentro de una misma propuesta didáctica, planificadas de manera coherente por el contenido o la temporalización. Sin embargo, gran parte de estas propuestas didácticas están diseñadas en función de las tareas, incluyendo, en muchas de ellas actividades procedimentales que no desarrollan un aprendizaje activo por parte del alumnado. Pocos recursos avanzan de esta limitación didáctica y recogen propuestas pedagógicas más activas que favorecen la creación o la investigación, por proyectos, especificando en su REA el uso de este recurso por rincones, favoreciendo el trabajo colaborativo y que proponga el desarrollo de propuestas didácticas con las familias $(n=7)$. Es de destacar que cada REA se está analizando de forma independiente y exclusivamente con la información que aparece en él. Por lo tanto, es posible que detrás de ese REA haya una propuesta mayor que favorezca esa tendencia activa en el aprendizaje, aunque en base a lo que acontece al propio recurso parecen desarrollar en su generalidad una tendencia de corte conductista, con mucha exposición del contenido y con actividades tipo cuestionario, de selección o de completar con palabras.

Los recursos de tipología exelearning, por su propia lógica secuencial y detallada en torno a una propuesta didáctica, en su mayoría recogen brevemente los objetivos de aprendizaje. En el caso de los otros recursos con formatos diversos, encontramos algunos apartados donde se especifica esa información ya sea en la propia web donde se encuentran alojados o en el propio recurso. Estos otros recursos están más relacionados para el propio uso del alumnado por lo que no desarrollan tanto la información pertinente a la propuesta didáctica dirigida al interesado profesional. Además, en cuanto a la atención a la diversidad, en gran parte ninguno de los REA profundiza la necesidad de la atención educativa específica. No obstante, en algunos casos se menciona que las actividades pueden ser adaptadas o que se pueden seleccionar según el 
interés. Aunque no haya una mención directa detallada, en el caso de los recursos cerrados de carácter institucional se encuentra un botón dedicado a favorecer la accesibilidad. Los recursos exelearning permiten su descarga y al ser software libre, permite la modificación y adaptación, cuestión necesaria e interesante que no lo ofrece los otros materiales de tipología cerrada.

\subsection{Dimensión de los contenidos}

Por otro lado, en cuanto a la dimensión de los contenidos, se destaca positivamente los materiales que tratan temas transversales, además de las áreas del currículo de Educación Infantil. En general, las temáticas que abordan elementos cercanos al alumnado o sus personajes son atractivas e identificables. Siguiendo el análisis, en pocos recursos educativos en abierto $(n=6)$ se menciona que los contenidos y actividades se pueden seleccionar según el interés y según las necesidades del alumnado, aunque el profesorado puede realizar ese esfuerzo. En algunos MDD, además, incluyen actividades, contenidos y elementos complementarios, por lo que se pueden tener en cuenta para el refuerzo o para ampliar información en el alumnado que lo precise.

El contenido, representado en formato textual, en algunos casos de REA diseñados en exelearning parece intercalar párrafos destinados al profesorado (evidente por su contenido y dificultad gramatical) con secciones que podría estar pensada para que lea el alumnado, lo cual genera cierta confusión. Esta situación no se da en los otros REA, que sí mantienen una coherencia en torno al colectivo de destino, elaborados íntegramente con imágenes, vídeos y con textos pensados directamente para niños y niñas de Infantil.

Los otros formatos de representación de la información como los vídeos o los audios, están dirigidos al alumnado de Infantil en todos los casos y se aprecia una gran diversidad en torno a las características técnicas, temáticas y objetivos. En algunos casos, estos recursos audiovisuales son animados por personajes de dibujo, que favorecen la cercanía al contenido, y en otros casos, aparecen imágenes de edades similares al colectivo de destino. El contenido de los recursos educativos seleccionados no favorece, en su mayoría, el conocimiento en torno a la diversidad sociocultural ni política, aunque sí se encuentran algunos materiales sensibilizados y destinados a la coeducación y a la atención a la diversidad.

\subsection{Dimensión evaluativa}

Por último, en cuanto a la evaluación, de los 24 materiales analizados, menos de la mitad especifican los criterios de evaluación, estándares de aprendizaje y/o indicadores $(n=11)$. Las actividades de evaluación destinadas al alumnado son de tipo cuestionario de respuesta verdadero o falso y correcto o incorrecto $(n=12)$. En cuanto a los materiales destinados al profesorado, no se incluyen actividades evaluables. De las actividades de autoevaluación recogidas en los MDD analizados, encontramos unas que ofrecen un feedback sonoro ( $n=2)$ y otras que ofrecen retroalimentación visual $(n=5)$. Los momentos de la evaluación más comunes son los finales y procesuales.

Al tratarse de materiales destinados a la Educación Infantil, encontramos como método de evaluación la observación en tres de las actividades propuestas en ellos. Por otro lado, hemos encontrado cuatro materiales, entre los analizados, que no incluyen actividades de evaluación ni propuestas de criterios, estándares de aprendizaje o indicadores que orienten la evaluación del alumnado. Hay un material destinado al trabajo del alumnado en los hogares, que menciona, aunque no detalla cómo hacerlo, la evaluación del propio material que permita identificar las potenciales mejoras del material. 


\section{DISCUSIÓN}

Tras analizar la muestra de recursos seleccionados, los resultados obtenidos nos muestran cómo, gran parte de los materiales que alberga el portal Procomún del INTEF, se podrían catalogar como REA, según la definición de UNESCO (2012). Muchos de estos recursos educativos cuentan con la estructura bien definida: portada, descripción, tareas de desarrollo, tareas finales, guía didáctica y ficha técnica. Su propia naturaleza permite seguir la filosofía de "conocimiento abierto" que ya mencionaba Pastrana (2018) basada en crear, compartir, usar, recrear y volver a compartir.

Para la discusión de este trabajo, es relevante prestar especial atención a las clasificaciones de materiales didácticos presentadas anteriormente en la introducción. Acorde con la clasificación de Hansen (2010, citado en 2019), se puede hablar en su mayoría de "Materiales didácticos de aprendizaje". Estos se caracterizan por tener una intencionalidad didáctica, de tal forma que el material tenga una didáctica asociada. Tienen una finalidad concreta: identificar objetivos específicos de la asignatura, comunicar contenido, enmarcar actividades y tareas, apoyo a los estudiantes, etc. Este término se puede relacionar a su vez con la categorización de Area (2017), en la que establece el término "Material Didáctico Digital (MDD)". En este caso, se trata de materiales estructurados, dirigidos a facilitar al alumnado el desarrollo de experiencias de aprendizaje en torno a unos contenidos o competencia. Su uso suele estar ligado a la educación formal, ya que los contenidos didácticos parten de una normativa y elementos curriculares.

Los recursos didácticos atienden no solo a tratar los contenidos propios del área de aprendizaje del currículo de la etapa de Educación Infantil, también se pretende iniciar al alumnado en el uso de recursos digitales de forma transversal a su aprendizaje. En este sentido, está presente el discurso de Caldeiro-Pedreira y Castro-Zubizarreta (2020), en el que describen cómo los recursos digitales en cualquier etapa educativa deben atender también a una adecuada alfabetización mediática y digital.

En cuanto a los criterios de calidad según la Norma 71362 de "Calidad de los materiales educativos digitales", hemos podido comprobar que la mayoría de los materiales analizados no cumplen con la robustez y estabilidad técnica que se espera. Esto concuerda con el estudio realizado por Chirino et al. (2018), cuando señalan que se demanda una actualización de los recursos educativos allí alojados, para poder cumplir con este criterio de calidad de los mismos. Otro de los criterios que hemos visto menos desarrollado en los materiales analizados, está relacionado con la adaptabilidad de los mismos, ya que no se ajusta al nivel y estilos de aprendizaje del alumnado, como tampoco explota diferentes caminos para alcanzar los objetivos didácticos.

Sin embargo, y siguiendo los criterios de la Norma nombrada con anterioridad, hemos podido observar que la mayoría de los MDD cumplen una serie de criterios de calidad que son de interés en este apartado destacar. En cuanto a la dimensión tecnológica, se destaca la navegación de los recursos, ya que con el título de las secciones que comprenden el material, se puede acceder correctamente a información relevante dentro del mismo recurso. De este modo, el medio aporta distintas rutas para llegar a más información, y además mantiene suficientes indicadores de posición que indican dónde se encuentra el usuario dentro del recurso. Otro criterio de calidad a destacar es el referido a la "interactividad", ya que nos encontramos recursos que aseguran la interacción del alumnado con el mismo, contiene actividades diversas, el aprendizaje es dirigido y se registra el progreso en dichas actividades, aunque esto último no está presente en todos los materiales analizados. 
Para terminar con los criterios de calidad establecidos en la norma, es necesario nombrar aquellos más relacionados con las dimensiones pedagógicas y de contenido. En cuanto a la descripción didáctica de los mismos, la mayoría ofrece los objetivos didácticos, los receptores a los que va dirigido, las competencias o áreas que desarrolla e incluye indicaciones para su uso. Esta descripción del recurso aporta valor y coherencia didáctica al mismo. Por otro lado, en cuanto a la capacidad que tienen los materiales de generar aprendizaje en el alumnado, observamos que, dependiendo del material analizado, algunas cumplen con una función didáctica interesante a favor de promover el aprendizaje significativo, la creatividad e innovación, y estimula el espíritu crítico y la reflexión.

\section{CONCLUSIONES}

Entre las principales conclusiones en torno a los recursos analizados, es de destacar, como aspectos a mejorar, la descontextualización de las actividades por varios motivos: porque mezcla contenidos de distintas materias sin conexión entre ellas o porque el MDD propone actividades comunicativas por medio de la expresión escrita cuanto está destinado a alumnado que no ha adquirido las competencias de lectoescritura básicas para su comprensión, la carencia de una propuesta didáctica que pueda sustentar el valor del material como susceptible de ser utilizado en las aulas de educación infantil y el planteamiento de actividades que no se pueden resolver de manera autónoma. Estas dificultades afectan al posible uso didáctico y autónomo de estos recursos didácticos por el alumnado de Educación Infantil y demandan un esfuerzo por parte del profesorado para integrarlos como recursos interesantes en el proceso de enseñanza y aprendizaje. Esta conclusión coincide con lo expuesto en diferentes estudios, donde se afirma que el papel del docente en este proceso es fundamental para el uso correcto de los recursos digitales (Sanabria et al. 2017; Gabarda et al. 2021).

Las propuestas metodológicas que promueven la creatividad, imaginación y la posibilidad de ser utilizadas de manera cooperativa o en pequeños grupos en el aula, representan un valor pedagógico en sí mismo. Precisamente por ello, los recursos didácticos que integran estas tendencias activas para el desarrollo del aprendizaje son muy relevantes e interesantes, pero son una minoría entre los analizados. Esto se relaciona con el estudio realizado por Peirats et al. (2019), en el que los docentes mostraron su preocupación por el individualismo que se fomenta al trabajar con dichos materiales. Gran parte de los recursos didácticos no superan esa tendencia en torno a actividades de carácter procedimental, cuestión que también se aprecia en las formas de evaluación de esos contenidos. El feedback de estas actividades de carácter procedimental que, en su mayoría integran los materiales analizados de forma absoluta o complementario, ya sean sonoros, visuales o textuales (verdadero, falso y correcto, incorrecto), no ofrecen al alumnado una posible alternativa para conocer cuál ha sido el error o cómo encontrar la respuesta correcta, por lo que este sistema de evaluación en algunos materiales no resulta constructivo. Además, en los materiales analizados no existe la posibilidad de recurrir a los conocimientos previos del alumnado, mediante una evaluación inicial, ni tampoco ofrecen recomendaciones de utilidad para la atención a las necesidades educativas especiales.

Las dificultades técnicas apreciadas también pueden afectar a la utilidad de estos recursos para la práctica diaria, ya que encontramos materiales cuyos enlaces a las actividades están desvinculados o requieren de la actualización de complementos en la navegación. Esto junto con la falta de interactividad de algunos materiales y el uso de sistemas de comunicación poco adaptados a la edad infantil, son los aspectos tecno- 
lógicos que requieren de una revisión para optimizar el potencial del material. La necesidad de implementar complementos en el navegador o la actualización de su interfaz, invita a pensar que los MDD creados requieren de una actualización periódica y para ello es necesario evaluar el propio material. Por lo tanto, no es suficiente con crearlo y compartirlo, es preciso actualizar sus condiciones técnicas, pedagógicas y su diseño, casi al mismo ritmo que avanzan los procesos educativos en la red. Esto coincide con el estudio Chirino et al. (2018) en el que describen la necesidad de actualizar los recursos albergados para cumplir con los estándares de calidad. Esta conclusión nos sugiere la importancia de que todos los agentes educativos implicados en los procesos de enseñanza-aprendizaje estén en constante colaboración, pues es la única manera de poder conseguir recursos educativos digitales de calidad. Además, no solo hay que atender a los requerimientos técnicos sino también al uso que se haga de estos materiales por parte del profesorado. Es necesario recordar, tal y como indican Caldeiro-Pedreira y Castro-Zubizarreta (2020), que los MDD en todos los contextos educativos deben velar por una adecuada alfabetización mediática y digital.

No podemos afirmar que los MDD analizados cumplen todos los criterios de calidad según la Norma 71362 de "Calidad de los materiales educativos digitales", que establece la Asociación Española de Normalización (UNE), la cual, como se ha dicho con anterioridad, tiene por objeto contribuir al desarrollo de los sectores de actividad, a través de las reglas técnicas, orientando los esfuerzos de todas las partes interesadas. En este sentido, es necesario estandarizar esta u otra normativa en cualquier proceso de creación de materiales didácticos digitales, para favorecer la creación de recursos educativos de calidad, siendo estos reutilizables y aplicables a cualquier contexto. Recordemos que, según esta norma, un recurso educativo es de calidad si es eficaz didácticamente y para saberlo, es necesario evaluar de forma precisa los materiales, su utilización, y los resultados obtenidos. Por otra parte, la eficacia tecnológica y la accesibilidad tampoco están contrastadas, la primera, porque muchos de ellos no son modificados a medida que se implementan nuevos usos tecnológicos y en cuanto a la accesibilidad, tampoco se han medido las dificultades para su uso. De hecho, como ya hemos mencionado, encontramos enlaces rotos, necesidad de actualizar complementos o vínculos. Para favorecer esta medida, la propia plataforma de Procomún debería filtrar los materiales albergados atendiendo a estos criterios, dando lugar a un portal mucho más rico en contenido utilizable por la comunidad educativa.

No obstante, y, por último, es de mencionar que se necesita completar este estudio con resultados empíricos que demuestren la utilización y consulta que realiza el profesorado en esta plataforma y en el caso de las actividades de aula, conocer los resultados de aprendizaje del alumnado que ha utilizado el recurso.

\section{REFERENCIAS}

Area, M. (2009). Introducción a la Tecnología Educativa. https://www. observatoriodelainfancia.es/ficherosoia/documentos/2027 d Introduccion a la tecnologia educativa.pdf

Area, M. (2017). La metamorfosis digital del material didáctico tras el paréntesis Gutenberg, RELATEC: Revista Latinoamericana de Tecnología Educativa, 16(2), 13-28.

Area, M. (2019). Reinventing Schools and Educational Materials in the Digital Society. En J. Rodríguez, T.M., Braga, y E.
Bruillard (Coords.), IARTEM 1991-2016: 25 years developing textbook and educational media research (pp. 371-376). Andavira. https://iartemblog.files.wordpress.com/2019/09/iartem 25 years.pdf

Caldeiro-Pedreira, M. C., \& Castro-Zubizarreta, A. (2020). ¿Cómo enfrentar la educación en la era de la interactividad? Recursos y herramientas para docentes de educación infantil y primaria. Praxis Pedagógica, 20(26), 33-53. https://doi. org/10.26620/uniminuto.praxis.20.26.2020.33-53 
Chirino, E., Romero, K.E., Castro, J.J., \& Etopa, M.P. (2018). Análisis de portales con materiales didácticos digitales: Procomún y EcoEscuela 2.0. En: E. López, D. Cobos, A.H. Martin, L. Molina, A. Jaén (Coords.), Experiencias pedagógicas e innovación educativa: aportaciones desde la praxis docente e investigadora (pp. 3161-3170). Octaedro.

Gabarda, V., Marín, D., \& Romero, M. (2021). Evaluación de recursos digitales para población infantil. EDMETIC, 10(1), 135-153. https://doi.org/10.21071/edmetic.v10i1.13125

Hansen, T. I. (2019). Reinventing Schools and Educational Materials in the Digital Society. En J. Rodríguez, T.M., Braga, y E. Bruillard (Coords.), IARTEM 1991-2016: 25 years developing textbook and educational media research (pp. 377-383). Andavira. https://iartemblog.files.wordpress.com/2019/09/ iartem 25 years.pdf

Pastrana, A. M. (2018). Los recursos educativos abiertos (REA) y su contribución a los procesos de enseñanza y aprendizaje en la educación secundaria. https://bit.ly/2PqB3Rz

Peirats, J., Eirín, R., \& Rodríguez, J. (2019). Visiones de los agentes implicados en el diseño, difusión y utilización de los materiales digitales educativos en portales educativos españoles. Educar em Revista,35(77), 37-58. https://doi. org/10.1590/0104-4060.68386

Santana, P., Eirín, R., \& Marín, D. (2017). Análisis y evaluación de portales institucionales en España. Los casos de Canarias, Galicia y Valencia. RELATEC: Revista Latinoamericana de Tecnología Educativa,16(2), 29-48. http://doi.org/ $10.17398 / 1695-288 X .16 .2 .29$

Sanabria, A., Álvarez, Q., \& Peirats, J. (2017). Las políticas educativas en la producción y distribución de materiales didácticos digitales. RELATEC: Revista Latinoamericana de Tecnología Educativa, 16(2), 63-77. http://dx.medra.org/10.17398/1695$288 \times .16 .2 .63$

Rodríguez, J., Braga, T., \& Bruillard, E. (2019). IARTEM 1991-2016: 25 years developing textbook and educational media research. Andavira.

UNESCO. (2002). Forum on the impact of open courseware for higher education in developing countries: Final report. https:// unesdoc.unesco.org/ark:/48223/pf0000128515

\section{ANEXOS}

Alacid, B. (21 de Marzo de 2020). El caballito de mar. Procomún, INTEF.https://url.comhttp://procomun.educalab.es/es/ode/ view/1571379884837

Alejo, C. (02 de Diciembre de 2019). La alimentación en educación infantil. Procomún, INTEF. http://procomun.educalab.es/es/ode/ view/1571379877173

Blanco, S. M. (05 de Noviembre de 2020). El planeta está en peligro, ¿nos ayudas? Procomún, INTEF. http://procomun.educalab.es/ es/articulos/el-planeta-esta-en-peligro-nos-ayudas

Braña, M. (12 de Noviembre de 2020). ¡Vamos a conocer los números!. Procomún, INTEF. http://procomun.educalab.es/es/ode/ view/1594714762793

Cardeñosa, C. (13 de Febrero de 2017). Teselados, creando motivos decorativos. Procomún, INTEF. http://procomun.educalab.es/ es/articulos/teselados-creando-motivos-decorativos-1

Díaz, V. (11 de Noviembre de 2020). Mar de palabras. Procomún, INTEF. http://procomun.educalab.es/es/articulos/mar-de-palabras

Domínguez, C. (16 de Diciembre de 2019). La bruja boba. Procomún, INTEF. http://procomun.educalab.es/es/ode/ view/1571379878491

Esparza, R. (22 de Febrero de 2018). La ratita manitas. Procomún, INTEF. http://procomun.educalab.es/es/ode/view/1519042222111 Fernández, E. (13 de Diciembre de 2016). Los colores. Jarabe de palo \& Modá. Procomún, INTEF. http://procomun.educalab.es/es/ ode/view/1445270077365

García, F. (11 de Noviembre de 2020). El espacio. Procomún, INTEF. http://procomun.educalab.es/es/ode/view/1594714762650

Gil, M. E. (11 de Noviembre de 2020). Mi cuerpo por dentro. Procomún, INTEF. http://procomun.educalab.es/es/ode/ view/1594714762696

Lozana, M. V. (06 de Mayo de 2020). La tortuga boba. Procomún, INTEF. http://procomun.educalab.es/es/ode/view/1571379891336 Martín, M. (20 de Mayo de 2014). Abecedario. Procomún, INTEF. http://procomun.educalab.es/es/ode/view/1416349627394 
Martín, M. (17 de Noviembre de 2020). REA. Una vuelta al otoño. Procomún, INTEF. http://procomun.educalab.es/es/articulos/rea-una-vuelta-al-otono

País Vasco (13 de Diciembre de 2016). Los gestos con las manos. Procomún, INTEF. http://procomun.educalab.es/es/ode/ view/1416349690998

Penyagolosa e-duca. (17 de Mayo de 2020). Juegos de matemáticas online. Procomún, INTEF. http://procomun.educalab.es/ es/articulos/juegos-de-matematicas-online

Pintado, L. (14 de Octubre de 2020). El poder de las emociones: la ira. Procomún, INTEF. http://procomun.educalab.es/es/ode/ view/1594714757815

Quicler, A. (03 de Noviembre de 2020). Érase una vez mi cuento. Procomún, INTEF. http://procomun.educalab.es/es/ode/ view/1594714760155

Rodríguez, C. (22 de Octubre de 2019). Unidad didáctica para la coeducación en educación infantil. Procomún, INTEF. http:// procomun.educalab.es/es/ode/view/1571379873287

Rodríguez, T. (3 de Diciembre de 2019). Cuento para armar. Procomún, INTEF. http://procomun.educalab.es/es/ode/ view/1571379877231

Sala, B. (10 de Noviembre de 2015). ¿Qué hay en mi carrito? Procomún, INTEF. http://procomun.educalab.es/es/ode/ view/1445270079022

Serrano, M. (03 de Noviembre de 2020). Proyecto "Hojas de otoño". Procomún, INTEF. http://procomun.educalab.es/es/ode/ view/1594714760271

Siles, R. (02 de Enero de 2021). Preleo. Procomún, INTEF. http:// procomun.educalab.es/es/ode/view/1594714766883

Valverde Jiménez, A. (01 de Mayo de 2020). La cuna de los Juegos Olímpicos. Procomún, INTEF. http://procomun.educalab.es/ es/ode/view/1571379890780 